\title{
¿QUÉ PUEDE EL PENSAMIENTO DE PAULO FREIRE EN TIEMPOS OSCUROS? PROBLEMAS ACTUALES EN TORNO A LA OSADÍA Y ALGUNOS MODOS DE EX/RES/ISTENCIA EN BRASIL Y ARGENTINA
}

\author{
WHAT CAN PAULO FREIRE'S THINKING DO IN DARK TIMES? CURRENT \\ PROBLEMS AROUND DARING AND SOME MODES OF EX / RES / ISTENCIA IN \\ BRAZIL AND ARGENTINA
}

Heloísa Andreia de Matos Lins Doutora em educação pela Universidade Estadual de Campinas e Professora do Departamento de Psicologia Educacional desta mesma IES.

Norma Elena Bregagnolo

Professora em Educación Pre Elemental e Especialista em Jardines Maternales, pela Universidad Nacional del Nordeste de Argentina (UNNE). Mestranda em Metodologia da Pesquisa Científica na UNNE.

\begin{abstract}
El problema es actuar sin estar paralizado por el miedo [...] Si no controla su miedo, deja de correr riesgos, no crea nada. Sin riesgo, para mí, no hay posibilidad de existir (Paulo Freire, 1986, p. $42^{1}$ ).
\end{abstract}

\begin{abstract}
Resumen: Este artículo analiza los modos actuales de oscurantismo en países como Brasil y Argentina, donde el legado de pensamiento de Paulo Freire se vuelve fundamental para subsidiar nuevos modos de re/ex/istencia a las imposiciones hegemónicas de la formación humana y docente. Exactamente por el poder de su pensamiento, el trabajo analiza algunos elementos de la narrativa de gran parte de la sociedad brasileña que violentamente comienza a vilipendiar, también a través de un proyecto gubernamental, las enseñanzas de este pensador reconocido internacionalmente. Contra estos ataques, el texto presenta un proceso de formación docente que puede materializar la importancia de crear utopías en estos contextos, por vislumbrar otras existencias e formas de vida, más dignas y justas.
\end{abstract}

Palabras Clave: Existencias. Formación docente. Oscurantismo. Paulo Freire. Resistencias.

\begin{abstract}
This article discusses current modes of obscurantism in countries such as Brazil and Argentina, where Paulo Freire's legacy of thought becomes fundamental to subsidize new modes of resistance-existence to the hegemonic impositions of human and teacher formation. Exactly by the power of his thought, the work analyzes some elements of the narrative of much of Brazilian society that violently begins to vilify - also through a government project - the teachings of this internationally recognized thinker. Against these attacks, the work presents a process of teacher training that can materialize the importance of creating utopias in these contexts, for glimpsing other more worthy and just existences and life forms.
\end{abstract}

Keywords: Existences. Teacher training. Obscurantism. Paulo Freire. Resistances.

Resumo:Este artigo discorre sobre modos atuais de obscurantismo em países como o Brasil e Argentina, em que o legado do pensamento de Paulo Freire torna-se fundamental para subsidiar novos modos de relex/sistência às imposições hegemônicas de formação humana e docente. Exatamente pela potência de seu pensamento, o trabalho analisa alguns elementos da narrativa de boa parte da sociedade brasileira que violentamente passa a vilipendiar - por meio também de um projeto de governo - os ensinamentos desse pensador, reconhecido internacionalmente. Na contramão desses ataques, o trabalho apresenta um processo de formação de docentes que pode materializar a importancia da criação de utopias nesses contextos, por vislumbrar outras existências e formas de vida, mais dignas e justas.

Palavras-Chave: Existências. Formação docente. Obscurantismo. Paulo Freire. Resistências.

Citar como - (ABNT NBR 6023:2018)

LINS, Heloísa Andreia de Matos; BREGAGNOLO, Norma Elena. ¿Qué puede el pensamiento de Paulo Freire en tiempos oscuros? Problemas actuales en torno a la osadía y algunos modos de ex/res/istencia en Brasil y Argentina. Eccos - Revista Cientifica, São Paulo, n. 52, p. 1-15, e17101, enero/marzo 2020. Disponível em: https://doi.org/10.5585/eccos.n52.17101. 


\section{El pensamiento y la discusión de Freire sobre los modos de re/ex/istencia en el Brasil actual: un escenario sobre la educación}

Brasil se ha convertido en un terreno aún más amplio y fértil para el odio y el miedo, teniendo en cuenta su historia de autoritarismo y violencia, como también nos recordó la historiadora y antropóloga Lilian Schwarcz (2019). Quienes viven aquí y tienen sensibilidades mínimas hacia los demás/la naturaleza puede estar de acuerdo. Aquellos que con mucho analizan lo que está sucediendo en las relaciones brasileñas, más recientemente, pueden resumir así: "No se puede hacer una antigua dictadura que se imponga con el ejército, sino una dictadura orwelliana para ocupar las mentes", como hizo Manuel Castells (2019, nuestros subrayados²). El sociólogo español continúa en la misma entrevista: “... pensar es peligroso. [...] Por lo tanto, digo que es una dictadura, aunque sea un tipo nuevo. Es una dictadura de la era de la información".

En otra ocasión, aún en 2015, frente al mito de la simpatía brasileña, Castells destaca las contribuciones de Internet a la manifestación y organización de grupos sexistas y racistas, por ejemplo, que "pueden declararse abiertamente así. En la red, no hay vergüenza y se abre la posibilidad de una expresión espontánea de la sociedad". Ante este fenómeno reciente, se observa que "la sociedad es bastante mala. En Brasil y en todos los demás países" (CASTELLS, $2015^{3}$ ). En este sentido, estamos de acuerdo con esta comprensión y con el hecho, también destacado por el investigador, de que tales movimientos son principalmente emocionales.

En esta dirección, Sami Naïr, profesor de Ciencias Políticas de la Universidad de París, afirma en un reciente artículo publicado por el periódico El País ${ }^{4}$, entre otros análisis tejidos sobre el discurso de odio que ha ganado terreno en varios países:

\footnotetext{
[...] la lucha contra el neofascismo debe ser asumida firmemente, explicar claramente a la población el peligro que plantea y proponer pactos democráticos antifascistas a aquellos que defienden la democracia y el respeto a la igualdad y la dignidad humana, al tiempo que denuncian, aquellos que pisotean estos valores por razones electorales. Debe lucharse una lucha diaria contra el populismo nacional neofascista, ya que la defensa de la democracia, el bienestar social, los derechos y las libertades deben ser permanentes. ¡Ojalá todos entiendan esto, porque es el futuro de la paz social!
}

Evidentemente, en este contexto ultraconservador (e incluso reaccionario, como se comentó anteriormente, en algunos casos, como la persecución y el exterminio de ciudadanos LGBTQIA + que solo crecen, convirtiendo al país en la primera posición en el "ranking mundial" de asesinatos ${ }^{5}$ ), las ideas de Paulo Freire se volvieron abominables para grupos impulsados por el odio y/o el miedo (mucho más allá del pensamiento y la práctica neoliberal/conservadora que se estaba desarrollando en el país). 
Un ejemplo de una especie de "pico" de este movimiento en el campo de la educación fue el "programa gubernamental" presentado por la lista de candidatos federales del entonces ejecutivo - diapositivas, de hecho, que condensaron las principales banderas ideológicas del espectro ultraderechista ${ }^{6}$ - que propone, entonces: "necesitamos revisar y modernizar el contenido. Esto incluye la alfabetización, la purga de la ideología de Paulo Freire, el cambio de la Base Nacional Curricular Común (BNCC), la prevención de la aprobación automática y el problema mismo de la disciplina dentro de las escuelas".

En esta misma confrontación con tal "ideología de Paulo Freire" (materializada en las acciones de los maestros ahora llamados "adoctrinadores") - "el mal" que habría afectado la educación en el país (equivalente a lo que ellos también conciben como "ideología de género", " "izquierdista", "femismo", "gayzismo ${ }^{7 "}$ etc., son lados de la misma moneda), explicando cualquier falla en el campo y ataques militarizados a las escuelas (a partir de 2020, ya en curso, principalmente a través de Enmienda Constitucional 101/2019 ${ }^{8}$ ) - la propuesta se lanza luego en el período preelectoral: "El contenido y el método de enseñanza deben cambiarse. Más matemáticas, ciencias y portugués, sin adoctrinamiento y sexualización temprana. Además, la prioridad inicial debe ser la educación básica y la educación secundaria/técnica" (énfasis agregado).

Recientemente, además de los anuncios sobre escuelas militarizadas (las llamadas escuelas cívico-militares) emitidas por canales públicos de televisión ${ }^{9}$, en el sitio web oficial del Ministerio de Educación encontramos algunos argumentos sobre la necesidad de "disciplina" dentro de las instituciones escolares, fundamentalmente, además de otros señalados, como:

\begin{abstract}
Preferiblemente, el modelo se llevará a regiones con situaciones socialmente vulnerables y bajos Índices de Desarrollo de Educación Básica (Ideb), un indicador que mide la calidad de las escuelas públicas. Entre las premisas del programa se encuentra la contribución a la mejora del entorno de los profesionales de la educación y a la reducción de la violencia, la deserción, la repetición y las tasas de deserción ${ }^{10}$.
\end{abstract}

En la misma línea, sigues refiriéndonos a la diapositiva (46 de 81 páginas) del "programa gubernamental", hay una advertencia para la sociedad en general: "Uno de los males más grandes hoy en día es el fuerte adoctrinamiento", no por casualidad también una de las principales banderas del Movimiento de la Escuela sin Partido ${ }^{11}$, Movimiento de Brasil Libre, $\mathrm{MBL}^{12}$, Derecha de São Paulo ${ }^{13}$, incluso autodenominados maestros ultraderechistas/ultraconservadores, el Movimiento Maestros para la Libertad ${ }^{14}$ (entre otros), y también declara, sobre la base de "persecución desde la izquierda": No aceptaremos que nuestra 
visión del mundo esté tergiversada por ideas ajenas al concepto de Libertad"15, cuando el texto toca directamente uno de los fundamentos principales del pensamiento de Freire: la libertad para / aprender y enseñar.

También motivado por el clima "salvacionista" en torno de una mesmidad moral y existencial, entonces, sin constreñimiento, el Ministro de Educación, en una entrevista con Rádio Jovem Pan ${ }^{16}$, dispara (también argumentando que un "criterio científico probado" y "no se puede tomar de la oreja"): "Esto es conocido en todo el mundo, mira, la aspirina fue hecha por los nazis. Yo uso aspirina porque funciona. Paulo Freire, si fuera tan bueno, tendría al menos otro país además de Brasil utilizando su método. Cosa buena nosotros copiamos", afirmando (además de la información errónea explícita observada, sobre la influencia del pensamiento de Freire en el mundo) con completo desdén y desprecio que el erudito brasileño sería "feo para doler ", refiriéndose a la estatua del educador en MEC.

Además de los posibles significados en torno a la idea de la fealdad, un término utilizado por las fuerzas de poder eugenésicas en Europa a principios del siglo XX, teniendo como principal defensor en Brasil al médico Renato Kehl, quien, entre las décadas de 1910 a 1940, asumió la la propaganda eugenésica como misión política e intelectual, que le valió el título de "padre de la eugenesia en Brasil" (SOUZA, 2006).

En este contexto, es prácticamente inevitable, por lo tanto, que no recordemos a Hannah Arendt, sobre los orígenes y mecanismos del funcionamiento totalitario, cuando enfatiza algunas de las estrategias de este poder basadas en la inversión/ocultación de la realidad, a través del miedo y el odio hacia el otro, a lo "diferente" (a lo "feo"), en lo que llamó tiempos oscuros:

\begin{abstract}
Poseer poder significa la confrontación directa con la realidad, y el totalitarismo en el poder busca constantemente evitar esta confrontación manteniendo su desprecio por los hechos e imponiendo una estricta adherencia a las normas del mundo ficticio que ha creado. Ya no es suficiente que la propaganda y la organización establezcan que lo imposible es posible, lo increíble es verdad y una locura constante gobierna el mundo; El principal fundamento psicológico de la ficción totalitaria, el resentimiento activo contra el status quo, que las masas se negaron a aceptar como el único mundo posible, ya no existe, y cada fragmento de información concreta que se filtra a través del telón de acero, construido para detener el torrente siempre peligroso de la realidad desde el lado no totalitario es una mayor amenaza para el gobierno totalitario que la contra propaganda del movimiento totalitario. (ARENDT, 2012, p. 530, énfasis agregado)
\end{abstract}

En este sentido, reflexionar sobre las formas en que Paulo Freire se convierte en un enemigo público, gran parte de la sociedad civil y el Estado, implica la observación de regímenes totalitarios, su expresión violenta materializada y previamente conocida en las prácticas nazis, fascistas y comunistas, por ejemplo, y puede llevarnos a lo que se concibe como 
una sociedad distópica: lo que está diseñado para pensar en un mal lugar para un grupo en particular, "en el sentido de que invariablemente está amenazado, cazado, prohibido, oprimido, culminando en las posibilidades actuales de muerte/exterminio, el tónico es miedo y desconfianza" (CLAEYS, apud TALONE, 2018, p. 370), algo generalmente desencadenado por un régimen político, como enseña Gregory Claeys, profesor de Historia del Pensamiento Político en la Universidad de Londres.

Como se puede ver, si el pensamiento de Freire hubiera sido molesto - más allá de las dictaduras/autocracias, los fundamentos y las prácticas capitalistas y filosóficas neoliberales en las sociedades democráticas de baja densidad (SANTOS, 2019), obviamente arraigadas en la educación (orientada al mercado, por beneficio, en muchos casos) - en los regímenes neofascistas, como se entiende el gobierno actual (BOITO, 2019), la abominación de este nombre-pensamiento-movimiento-pluralidad, Freire, se realiza como una política moralizante ("edificante"), "bueno"/"científico"/"superior" /"necesario") y exterminio específico de su legado: una verdadera caza de brujas posmoderna (al "mago feo" de la conciencia, del la (indign)ación, autonomía, diálogo, amor, ética, solidaridad, esperanza, cambio, utopía y sueños, preguntas, entre muchas de sus banderas, y el "mal" causado por este tipo de pensamiento libertario, relacionado con la revelación. a tal "marxismo cultural ${ }^{17}$ ), con el derecho de fabricar todo tipo de mentiras: las llamadas deep fakes (falsificaciones profundas, como en el caso reportado por BuzzFeed ${ }^{18}$ ), así como las conocidas fake news (noticias falsas).

Por lo tanto, podría ser una patología colectiva/subjetiva también en tierras brasileñas (o algo similar a la banalidad del mal, en ARENDT, 2014), ya que nos ayuda a entender a la periodista brasileña Eliane Brum, en una reflexión importante y reciente. También publicado en el periódico El País ${ }^{19}$, que lamentablemente destaca la enfermedad de una gran parte de la población, debido al simple hecho de vivir en Brasil: "Sometido a una vida cotidiana dominada por la auto-verdad, un fenómeno que convierte la verdad en una elección personal y, por lo tanto, destruye posibilidad de la verdad, los brasileños han estado enfermos. Enfermedad mental, que también resulta en inmunidad reducida y síntomas físicos, ya que el cuerpo es uno".

Debido a este contexto más amplio, en el escenario pedagógico brasileño actual se disputan dos proyectos completamente diferentes: por un lado, la posibilidad de una "escuela viva" plural, un lugar de lo sensible y del diálogo, defendido por Freire como "donde puedes ser feliz", ser personas y en ele se "atar"20 y, por otro lado, la posibilidad de una "escuela de patrulla", da mesmidad, donde la normalización/igualdad, el control/denuncia/silenciamiento y los límites son el foco del proyecto de formación de un modo único de subjetividad: para el 
mercado (ver más detalles en AUTOR 1, 2019). Los otros modos de existencia (anormales) serían completamente prescindibles e incluso repudiables.

En resumen, el pensamiento de Freire hoy, en Brasil, confronta un proyecto de gobernanza de mentes y cuerpos, precisamente al activar modos plurales de existencia y resistencia a formas de opresión, a través del diálogo y la esperanza de un mundo más justo para todos.

Como señalaremos a continuación, al igual que en otros países, en Argentina ese pensamiento libertario continúa amenazando las políticas necrocapitalísticas (AUTOR 1), por supuesto también lo Neoliberalismo, pero también continúa prosperando algunos proyectos de formación docente, resistentes, cuando buscan alternativas contra hegemónicas y decoloniales a través de la educación. Cuando vislumbran otras existencias e formas de vida, más dignas y justas.

\section{Algunos impactos del pensamiento de Freire y los modos de ex/res/istencia en Argentina: un caso en la formación docente}

Las transformaciones hasta aquí mencionadas y que se han profundizado en estos últimos años, tras la embestida del Neoliberalismo, que "es debatido y confrontado como una teoría económica, cuando en realidad debe ser comprendido como el discurso hegemónico de un modelo civilizatorio" (ARROYO ORTEGA, p. 55), ha generado procesos de ajuste y transformaciones en la estructura social de Argentina, como de otros países de latinoamérica. De hecho, como explica Minujin (1997, p. 18), esto ha afectado a gran parte de la población, en especial, hacia el interior del país en donde ha generado concentración económica, contracción del Estado y retiro de sus funciones redistributivas, modificación en el mercado de trabajo con aumento de la precarización y el desempleo, caída del ingreso, aumento de la pobreza con la incorporación de sectores medios o nuevos pobres, entre otros.

Si bien en la República Argentina, la educación en todos los niveles y modalidades es un bien público y un derecho personal y social, que debería estar garantizado, en éstos tiempos, como otras instituciones que forman parte del Estado y en este caso las instituciones educativas, no han quedado ajenas a este debilitamiento de las funciones que le eran propias, sobre todo aquéllas que tenían que ver con garantizar los derechos de todos y todas, más aún cuando desde todas las propuestas que se desprenden de las legislaciones tanto nacionales como provinciales, así como de los documentos curriculares vigentes enfatizan la formación de una ciudadanía plena. Entre muchos otros puntos, baste con mencionar los siguientes: el artículo 11 de la ley 
Nacional de Educación n. ${ }^{\circ} 26206$ punto c) establece como fin y objetivo de la política educativa nacional "Brindar una formación ciudadana comprometida con los valores éticos y democráticos de participación, libertad, solidaridad, resolución pacífica de conflictos, respeto a los derechos humanos, responsabilidad, honestidad, valoración y preservación del patrimonio natural y cultural”. El artículo 20 de la misma ley al presentar a los niños y niñas de 45 días a 6 años como sujetos de derechos, está asimismo planteando como punto de partida una educación en ciudadanía de estos y estas estudiantes. Por otro lado, los Núcleos de Aprendizajes Prioritarios para el Nivel Inicial señalan en la introducción que "La función central de la escuela es enseñar para que niños y jóvenes adquieran los saberes que les permitan el ejercicio de una ciudadanía responsable y una inserción en el mundo."

Frente a esta realidad como formadores urge interpelar al propio "colonialismo interno" (CUSICANQUI, 2010), advierte Freire:

\footnotetext{
la ideología dominante "vive" dentro de nosotros y también controla la sociedad fuera de nosotros. Si esa dominación interna y externa fuera completa, definitiva, nunca podríamos pensar en la transformación social, pero la transformación es posible porque la conciencia no es un espejo de la realidad, es un simple reflejo, sinó que es reflexiva y reflectora de la realidad. (FREIRE, 2014, 34).
}

Desde esta perspectiva, avanzar en nuevos posicionamientos requiere la incorporación de las tendencias emergentes en investigación educativa y formación docente, para la producción de conocimiento desde una perspectiva crítica, que permitan desentrañar las estrategias de dominación que caracterizan al modelo eurocéntrico y que se imponen como modos de dominación del Neoliberalismo: el patriarcado, el colonialismo y el capitalismo (SOUSA SANTOS, 2017). Incorporación de las llamadas "epistemologías emergentes" (SOUSA SANTOS, 2009) como son las epistemologías del sur, las epistemologías feministas y las epistemologías de la reflexividad y complejidad, para educar desde y para una educación emancipadora, liberadora.

\section{Presentación del contexto y caracterización del grupo de estudiantes}

La Universidad Nacional del Nordeste (U.N.N.E.) es una de las universidades estatales ubicada en el nordeste del país; es regional porque está ubicada en la ciudad de Corrientes (Provincia de Corrientes) y en la ciudad de Resistencia (Provincia de Chaco), con Centros Regionales en otras localidades del interior de ambas provincias. Cuenta dentro de la Facultad de Humanidades con 6 (seis) Profesorados, 8 (ocho) Licenciaturas y 2 (dos) tecnicaturas. Dentro de estas ofertas de carrera de grado se encuentran el Profesorado en Educación Inicial 
que cuenta con más de 40 (cuarenta) años de trayectoria y la Licenciatura en Educación Inicial con 14 (catorce) años aproximadamente. Según informe realizado por Secretaría Académica de la Facultad de Humanidades, durante el año 2018, el total de los estudiantes ingresante para estas carreras se ubica en un $40 \%$ dentro de los estudiantes inscriptos en la Facultad de Humanidades.

El caso presentado corresponde a la asignatura Taller de Integración, Investigación y Práctica I, que corresponde al $1 .^{\circ}$ Nivel del Plan de estudio de las Carreras de Profesorado y Licenciatura en Educación Inicial, es de duración anual, pertenece al Área de la Intervención Docente, junto al Taller La Educación Inicial, los Talleres de Integración, Investigación y Práctica II, III y IV que lo suceden a lo largo de los cuatro niveles que tiene previsto el Plan, como así también Didáctica General, Didáctica de la Educación Inicial y Tecnología Educativa para la Educación Inicial. Posee una propuesta interdisciplinaria que trata de reducir la brecha entre teoría y práctica y a la vez, a través de una articulación horizontal, integrar saberes de otras cátedras de primer año. Entre sus propuestas el Taller busca que los distintos aportes disciplinares, se realicen al servicio de un tópico, en este caso el "Desarrollo y Educación: El Sujeto que aprende", conformando una suerte de "entretejido", donde los contenidos disciplinares sean resignificados a partir del eje problematizador.

A los efectos de poner en conocimiento las condiciones de dictado, cabe mencionar que el paso de la escuela media a la universidad genera una transformación de pautas de convivencia y desempeño de los estudiantes, que requiere de una etapa de iniciación y adaptación, y la incorporación de nuevas, diferentes y desafiantes formas de relación con el conocimiento:

\footnotetext{
... la sombra del sistema educativo previo a la universidad cae sobre la universidad, huellas de formas de conocer, sedimentos de eso que pasó antes, modos de estar, de relacionarse, unas huellas de relaciones de saber desvitalizadas, pisoteadas por el descuido al saber, manojos representacionales que, a veces, desde la propia institución construimos (FRIGERIO, 201721).
}

Entre las características más específicas con respecto al grupo de cursantes, es posible referir a las siguientes particularidades:

a) Masividad: al encontrarse en el primer nivel de la carrera la masividad es una de sus características, por ser ingresantes su número es elevado, el promedio anual es de 270 estudiantes, a los que se suman los recursantes, con los que, año a año, se llega a un total de 300 estudiantes, aproximadamente, a pesar de que hay otras ofertas en Institutos de Educación Superior, se sostiene la matrícula. 
b) Heterogeneidad: además de la masividad la heterogeneidad del grupo es otro factor que incide en el desarrollo del cursado. Es posible hablar de la heterogeneidad geográfica o de procedencia, la mayoría de las y los estudiantes proviene de Resistencia, del interior de las Provincias de Chaco y Corrientes, en menor medida de Misiones, Santa Fe y Formosa; en cuanto a estratos sociales son de sectores sociales diferentes, un grupo numeroso es de escasos recursos económicos, por lo que en su gran mayoría deben trabajar para solventar sus gastos y en ocasiones para sostener a la familia. En contraposición, cabe mencionar la homogeneidad existente en cuanto a las edades, hay un promedio de alumnos de 20 años de edad y en cuanto al género, la gran mayoría es de género femenino, por año hay entre uno o dos estudiantes de género masculino.

Con respecto a las competencias vinculadas a la expresión tanto oral como escrita se evidencian desempeños en ocasiones obstaculizados por la inhibición y la falta de lectura comprensiva; también esto se manifiesta en relación a la disponibilidad corporal frente a distintas propuestas.

En relación al uso de herramientas tecnológicas, fuera de la utilización de las redes sociales (twitter, Facebook), algunos desconocen la utilización de las herramientas básicas del programa Word y sobre cómo realizar búsqueda de información en páginas y revistas digitales, competencias estas transversales a todas las asignaturas y niveles del trayecto de formación docente inicial.

c) Diversidad de expectativas: Con respecto a las expectativas los estudiantes manifiestan diversos intereses, motivaciones, capacidades, que vienen teñidas con una dosis de mitos que pertenecen al imaginario social en relación a la profesión, al docente y al niño que es necesario deconstruir; se pone en juego también la creencia de que en los espacios curriculares predominan actividades manuales y poco desarrollo teórico. Se evidencia una visión reduccionista muy fuerte en relación a la educación infantil y a las posibilidades de desempeño profesional, limitada a la Educación Formal, específicamente a Instituciones de Nivel Inicial y al ejercicio profesional como maestros/as Jardineros/as desconociendo que existen otros formatos y otras posibilidades de ejercicio de la profesión.

En muchas oportunidades también la elección de la carrera está acompañada de una expectativa de ascenso social lo cual está vinculado con la "valoración de los estudios universitarios como recurso de movilidad social"' (ZABALZA, 2002, p.182). 
d) Diversidad de trayectos previos de formación: además se evidencia la diversidad en la trayectoria de formación - parte del grupo son graduadas o graduados del secundario y un alto porcentaje de estudiantes que poseen una trayectoria inconclusa en otros estudios de Nivel Superior -, profundizándose la diferencia en la formación disciplinar, los intereses de las y los estudiantes, las estrategias de estudio y fundamentalmente los recorridos previos.

Desde el equipo del Taller, a lo largo de los años se ha trabajado en forma colaborativa buscando estrategias y modalidades que optimicen la formación de los estudiantes ante esta realidad.

\section{Diseño y Desarrollo de la Propuesta}

Frente a esta realidad del grupo de estudiantes, las propuestas de enseñanza aprendizaje, se dan de manera articulada en el marco de la formación docente que inician las y los ingresantes al comenzar a cursar la carrera, dichas prácticas están “orientadas a la configuración de sujetos docentes/enseñantes" (ACHILLI, 2001, p. 23). Es necesario aquí como educadoras, desde un posicionamiento ético, político e ideológico, tener claro desde qué concepción de hombre y mujer partimos. Reconocemos a los sujetos, tal lo menciona Paulo Freire, como "seres históricos que se hacen y rehacen socialmente. Es la experiencia social la que en última instancia nos hace, la que nos constituye como estamos siendo (...) por lo que en cuanto seres históricos somos seres incompletos, inacabados o inconclusos" (FREIRE, 2009, p. 27,28). En este sentido reconocemos al sujeto como una construcción colectiva y compleja, considerando el valor que poseen tanto el bagaje cultural que han ido adquiriendo a lo largo de su escolaridad, como las huellas que empiezan a plasmarse como parte del proceso de formación inicial, por esto es que se estimula la necesidad de generar espacios dentro del desarrollo de los contenidos que permitieran a las y los estudiantes dar su voz y ser partícipes activos de un ejercicio de reflexión, respecto de sus propios procesos de formación y en la construcción del conocimiento.

Se intenta avanzar en saberes propios de los procesos de formación, es decir implicarlas e implicarlos en una "experiencia auténtica, significativa y común para volver a ella de una manera reflexiva, favorecer la construcción colectiva a partir de la experiencia, los intereses de los participantes y los interrogantes que las experiencias despiertan" (ANIJOVICH, 2009, p. 147), el taller genera así un espacio tiempo constructivo de intercambio, debate y escucha.

Pensar en un dispositivo que permita escuchar las voces de los y las estudiantes, es parte de reconocer que el acto educativo es en sí mismo un acto político, acto en el que se relacionan 
de una manera singular sujetos que enseñan y que aprenden, que comparten un tiempo y un espacio pedagógico. Siguiendo a Sklíar y Larrosa podemos decir que:

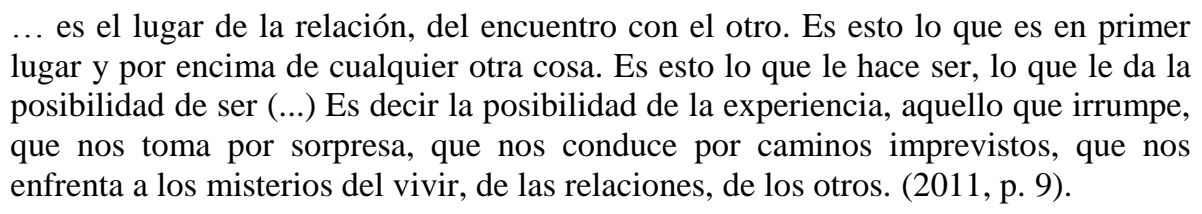

Se trabajó en un primer momento con narrativas biográficas, lo cual permitió reconocer aspectos que en la dinámica cotidiana pueden pasar inadvertidos, es aquí en donde los sujetos pueden mirarse, en palabras de Jorge Larrosa, tener una experiencia de sí, experiencia entendida como:

[...] eso que me pasa (...) supone un acontecimiento o, dicho de otro modo, el pasar de "algo que no soy yo" significa también algo que no depende de mí, que no es una proyección de mí mismo (...) Pero el lugar de la experiencia soy yo (...) Es en mí donde se da la experiencia, donde la experiencia tiene lugar. (LARROSA, 2011, p. 14 $-16)$.

Sus propias "experiencias" individuales plasmadas en un diario dieron lugar a la recuperación de sus propias historias escolares, explicitando representaciones sobre qué es ser docente y cómo debe ser un o una docente, qué es ser alumno o alumna y cómo debe ser un alumno o alumna, estereotipos con respecto a cómo enseñar, qué enseñar, quién enseña y quién aprende, representaciones con respecto a la organización del espacio y del tiempo, modelos pedagógicos internalizados.

En un segundo momento, en grupos eligen qué compartir de las narrativas de sus diarios, luego de intercambiar con el pequeño grupo, producen a partir de las narrativas compartidas, una dramatización, que es representada ante el grupo clase.

Al finalizar, durante la puesta en común, registran coincidencias más recurrentes como así también hechos que excepcionalmente se dan de manera diferente.

A partir de las lecturas de bibliografía específica de Paulo Freire realizan un proceso de análisis sobre las representaciones que hicieron y las narrativas. Uno de los conceptos claves de Paulo Freire que sensibilizó y movilizó al grupo fue la concepción de hombre como sujeto histórico e inacabado, esto contrasta con la tradición normalista argentina, de la cual están impregnadas sus historias escolares, donde el maestro/profesor es el que todo lo sabe, y desde un lugar de omnipotencia es el único que imparte conocimiento, desde una perspectiva de educación bancaria. 
Esta posibilidad de reconocimiento del inacabamiento a la vez que resignifica el sentido humano de la educación, los moviliza en su propio trayecto de formación haciéndolos tomar conciencia del protagonismo que tienen sobre este proceso como ciudadanos de derecho. Es el inicio de la deconstrucción de modelos interiorizados con respecto a qué es ser maestra/o o profesor/a, qué es ser alumno/a e iniciar un camino de búsqueda, habilitar la curiosidad que en muchos casos está dormida y sobre todas las cosas escuchar y escucharse, valorar lo que cada una/ sabe y puede, deja espacio a la duda y al debate para problematizar la realidad.

Cabe aclarar que desde el $1^{\circ}$ año las y los estudiantes tienen contacto con posibles campos de desempeño laboral, lo cual enriquece su mirada y genera nuevos insumos y desafíos para la discusión. Desde una mirada situada de la realidad, corriéndose de la visión de niños y niñas como "objetos discursivos", narrados desde textos y teorías escritas a partir de otras realidades, esta "experiencia" permite ampliar la mirada y la escucha hacia niños y niñas reales en sus propias "circunstancias", en un determinado contexto y momento.

La conciencia de la inconclusión del ser que se hace con otros, que está condicionado por un momento histórico, en un determinado contexto político, social y cultural es fundamental en la etapa de ingreso a la formación docente, porque exige una mirada desde la pedagogía crítica y un posicionamiento ético, desde la educación como acto político, donde el educador no es un mero trasmisor de conocimiento, sino que tiene la posibilidad y obligación ética de intervenir y transformar la realidad para mejorarla.

Reconocen aquí las y los estudiantes el valor del espacio y el tiempo pedagógico donde aprender a escuchar al alumno/a es una prioridad para comprender cómo y qué piensan de la realidad, analizan desde sus propias historias escolares el trabajo solitario que vienen haciendo en la escuela media, que genera una competencia individualista con sus pares, motivada por la meritocracia, el resignarse a callar, a autocensurarse por temor a equivocarse o a expresar sus sentimientos y pensamientos y que no sean aceptados o que sean desvalorizados.

Desde ese análisis valoran la posibilidad de trabajar de manera solidaria, sin subestimar lo que dicen y cómo nos dicen otros, por más pequeños/as que sean, bajo la convicción de que en el acto educativo tanto el docente como el/la educando niño/a, joven o adulto/a - enseñan a la vez que aprenden, como lo expresa Freire: "Saber que enseñar no es transferir conocimiento, es crear las posibilidades para a su producción o construcción (...) Quien enseña aprende al enseñar y quien enseña aprende a aprender.” (FREIRE, 2007, p. 47).

Es indispensable poner en juego la "curiosidad epistemológica" y llegar a una "violencia epistémica", que interpele a los propios participantes y que puedan interpretar sus decires como una expresión de los contextos sociales, políticos, económicos y morales en los que se han 
gestado. En este sentido, trabajamos con dispositivos de formación, donde concebimos la formación como un "desarrollo de la persona, centrado en la autoformación, donde los dispositivos actúan como mediadores de la formación y provocadores de cambio. Los dispositivos de formación no tienen la intencionalidad de transmitir saber sino de facilitar el desarrollo personal" (SOUTO,1999, p. 94).

Estamos convencidas que la educación y, en este caso, la Universidad, es una alternativa para la emancipación de ciudadanos y ciudadanas - jóvenes y adultos - en nuestros países de Latinoamérica.

Dado lo expuesto, como intentamos demostrar, en sociedades, como Brasil y Argentina, tan a menudo marcadas por el oscurantismo (salvaguardada las diferencias que ciertamente caracterizan a estos países), Paulo Freire continúa enseñando cómo contrarrestar las amenazas a la democracia y los modos recurrentes de una pedagogía colonizadora. Con él, aun así, podemos atrevernos a soñar, a crear utopías para la composición de resistencias en los tiempos actuales, ante el miedo y la impotencia, por ejemplo. Por lo tanto, con lo que nos enseñó el gran maestro sobre la osadía y la concientización, indignación, entre tantos saberes, podemos vislumbrar/ esperanzar cierta confrontación con el fascismo, Neoliberalismo, la negación de los diferentes modos de existencia y dignidad humana, a partir de los procesos sensibles e humanizantes de enseñanza-aprendizaje.

\footnotetext{
${ }^{1}$ Libre traducción (para todo el documento con ediciones en idioma portugués).

${ }^{2}$ Entrevista concedida a Jornal GGN, en 17.7.2019. Disponible en https://jornalggn.com.br/noticia/brasil-vive-novo-tipo-deditadura-orwelliana-de-ocupar-as-mentes-diz-castells/ .Acceso en 15.8.2019.

${ }^{3}$ Disponible en: https://www1.folha.uol.com.br/poder/2015/05/1630173-internet-so-evidencia-violencia-social-brasileiraafirma-sociologo-espanhol.shtml . Acceso en 25.08.2019.

${ }^{4}$ Disponible en: https://brasil.elpais.com/brasil/2018/12/07/internacional/1544180778_836431.html?rel=mas?rel=mas?rel=mas\&\%3Fid_ext erno_rsoc=TW_BR_CM\&hootPostID=942a5cd959f00507f15aaa4dcb97552f . Acceso en 12.01.2019.

${ }^{5} \mathrm{https}: / /$ www1.folha.uol.com.br/opiniao/2019/07/brasil-o-pais-da-diversidade-que-mais-mata-lgbtqia.shtml. Acceso en 02/09/2019. Véanse también los datos de la encuesta "Violencia de género y número contra la violencia electoral y post electoral", producida por Gênero e Número y financiada por la Fundación Ford, muestra que el $51 \%$ de los encuestados ha sufrido al menos un asalto desde las elecciones de 2018. los que más reportaron haber sufrido violencia (57\%), seguidos por personas trans y travestis $(56 \%)$, homosexuales $(49 \%)$ y bisexuales $(44.5 \%)$ :

https://brasil.elpais.com/brasil/2019/03/19/internacional/1553026147 774690.html. Acceso en 1/09/2019.

${ }^{6}$ Disponible en: http://divulgacandcontas.tse.jus.br/candidaturas/oficial/2018/BR/BR/2022802018/280000614517/proposta_153428463223 1.pdf. Ver también: https://www.bbc.com/portuguese/brasil-45767525. Acceso en 28.8.2019.

${ }^{7}$ Un ejemplo de este tipo de uso del término: https://revistaoconservador.wordpress.com/tag/gayzismo/. Acceso en 02.09.2019.

${ }^{8}$ En este sentido, ver http://www.in.gov.br/web/dou/-/emenda-constitucional-n-101-187433071. Acceso en 05.7.2019.

${ }^{9}$ Disponible en: https://www.youtube.com/watch?v=sDHWtyGgcYE . Acceso en 17.9.2019.

${ }^{10}$ Disponible en: http://portal.mec.gov.br/component/content/article?id=79931. Acceso en 17.9. 2019.

${ }^{11} \mathrm{https} / / / \mathrm{www}$.programaescolasempartido.org/. Acceso en 03.7.2019.

${ }^{12} \mathrm{http}: / / \mathrm{mbl}$.org.br/. Acceso en 04.07.2019.

${ }^{13} \mathrm{https} / / /$ direitasaopaulo.wordpress.com/. Acceso en 31.8.2019.

${ }^{14}$ Ver: https://revistaforum.com.br/escola-com-partido-professores-de-direita-lancam-movimento-nacional Acceso en $19 / 07 / 2019$.
} 
${ }^{15}$ Disponible en: https://www.gazetadopovo.com.br/educacao/perseguidos-pela-esquerda-professores-se-unem-pelaliberdade-no-ensino/ .Acceso en 01.09.2019.

${ }^{16}$ Disponible en: https://jovempan.uol.com.br/programas/jovem-pan-morning-show/entrevista-abraham-weintraub.html . Ver también en el periódico O Globo: https://oglobo.globo.com/sociedade/e-ou-nao-feio-de-doer-escreve-abraham-weintraubsobre-mural-de-paulo-freire-23848197 . Acceso a ambos en 31.8.2019.

${ }^{17}$ https://brasil.elpais.com/brasil/2019/04/14/politica/1555201232_670246.html. Acceso en 15.9.2019.

18 Disponible: https://medium.com/@ cssoaresonline/deepfake-voc\%C3\%AA-n\%C3\%A3o-vai-acreditar-no-que-barackobama-diz-neste-v\%C3\%ADdeo-3892287b375a. Acceso en 25.7.2019.

${ }^{19}$ Disponible en: https://brasil.elpais.com/brasil/2019/08/01/opinion/1564661044_448590.html . Acceso en 31.8.2019.

${ }^{20}$ En este sentido, ver https://oglobo.globo.com/sociedade/educacao/correcao-texto-escola-atribuido-paulo-freire-de-autordesconhecido-3180500. Acceso en 24/09/2019.ibre traducción (para todo el documento con ediciones en idioma portugués).

${ }^{21}$ FRIGERIO, G. Conferencia: "Saberes sobre los umbrales: sentidos que se ponen en juego en el ingreso a la universidad." VII Encuentro Nacional y IV Encuentro Latinoamericano sobre el ingreso universitario. Universidad Nacional de Cuyo UNCUYO -, Mendoza, Argentina. 2 al 4 de Agosto de 2017.Disponible en:http://www.unidiversidad.com.ar/elingresoalauniversidadgracielafrigerio?utm_campaign=canal_academico\&utm_term= 59\&fb_comment_id=1444316125665683_1615978661832761 28/09/2019. Acceso en 12.6.2019.

\section{Referencias}

ACHILLI, E. L. Investigación y formación docente. 2. ed., Rosario: Laborde Editor, 2001.

ANIJOVICH, R. Transitar la formación pedagógica: dispositivos y estrategias. Buenos Aires: Paidós, 2009.

ARENDT, H. Origens do totalitarismo: antissemitismo, imperialismo e totalitarismo. São Paulo: Companhia das Letras, 2012.

ARENDT, H. Eichmann em Jerusalém: um relato sobre a banalidade do mal. Tradução José Rubens Siqueira. São Paulo: Companhia das Letras, 2014.

ARROYO ORTEGA, A. Pedagogías decoloniales y la interculturalidad: perspectivas situadas en María Verónica Di Caudo, Daniel Llanos Erazo y María Camila Ospina (2016) (Coordinadores) Interculturalidad y educación desde el sur.-

BERTOLINI, M. La formación docente para la ciudadanía en contextos de neoliberalismo: propuestas desde las narrativas. Revista del Instituto de Investigaciones en Educación. Facultad de Humanidades UNNE. Año 8. n 10. 2017. Disponible en: http://hum.unne.edu.ar/revistas/educa/contenido10.htm. Acceso en 22.09.2019.

BOITO, A. O neofascismo no Brasil. Disponible em https://www.researchgate.net/publication/332592911_O_NEOFASCISMO_NO_BRASIL. Acceso en 28.8.2019.

BREGAGNOLO, N.E. El alumno ingresante al profesorado y licenciatura en educación inicial alternativas para evitar la deserción. Revista Estudios en Ciencias Humanas. Estudios y monografías de los posgrados. Universidad Nacional del Nordeste. Facultad de Humanidades. Secretaría de Investigación y Posgrado. n. 9. ISSN: 1851-8990, 2010. http://hum.unne.edu.ar/revistas/postgrado/revista9/articulos/seccion6/bregagnolo.pdf

CUSICANQUI, S. Ch'ixinakax utxiwa: una reflexión sobre discursos y prácticas descolonizadores. Buenos Aires: Tinta Limón, 2010. 
FREIRE, Paulo. Pedagogia da indignação: cartas pedagógicas e outros escritos. São Paulo: Ed. Unesp, 2000.

FREIRE, Paulo. Pedagogia da Esperança: Um reencontro com a Pedagogia do oprimido.. Rio de Janeiro: Paz e Terra, 1992 (Notas: Ana Maria Araújo Freire).

FREIRE, Paulo. SHOR, Ira. Medo e ousadia: o cotidiano do professor. Rio de Janeiro: Paz e Terra, 1986. (Coleção Educação e Comunicação, v.18).

FREIRE, Paulo. Miedo y Osadía. La cotidianeidad del docente que se arriesga a practicar una pedagogía transformadora Traducción Joaquín Martínez Ortiz. Buenos Aires: Siglo

Veintinuno, 2014.

LARROSA, J. Escuela, poder y subjetivación. Genealogía del poder. N26. La piqueta. España, 1995.

SKLIAR, C. y Larrosa, J. Experiencia y alteridad en educación. Rosario: Homo Sapiens, 2011.

MINUJIN, A. Cuesta abajo: los nuevos pobres: efectos de la crisis en la sociedad argentina. Buenos Aires: UNICEF Losada, 1997.

SANTOS, Boaventura Sousa. O fim do império cognitivo: a afirmação das epistemologias do Sul. Belo Horizonte: Autêntica Editora, 2019.

SANTOS, Boaventura Sousa. Una epistemología del sur: la reinvención del conocimiento y la emancipación social. México: Siglo XXI, Clacso, 2009.

SANTOS, Boaventura Sousa. Democracia y transformación social. Traducción de Jorge Davila, Bogotá: Siglo del Hombre; Siglo XXI 636; Paris: Gallimard., 2017.

SOUTO, M. Grupos y dispositivos de formación. Buenos Aires: Novedades Educativas, Serie Los Documentos n. 10, 1999.

TALONE, V.G. Distopias presentes, passadas e futuras:os monstros da sociedade. Sociologias, Porto Alegre, ano 20, n. 49, set-dez 2018, p. 368-380. Disponible em: http://www.scielo.br/pdf/soc/v20n49/1807-0337-soc-20-49-368.pdf. ACCESO em 29.8.2019.

TORRES SANTOME, J. Educación en tiempos de neoliberalismo. Madrid: Morata, 2001.

ZABALZA, M. La enseñanza universitaria en el escenario y sus protagonistas. España: Edit. Narcea. 2002. 